\title{
Proceeding
}

8th INSHS International Christmas Sport Scientific Conference, 5-7 December 2013. International Network of Sport and

Health Science. Szombathely, Hungary

\section{Temporal gait characteristics in the Czech adult population}

\author{
KORVAS PAVEL , HELLEBRANDT VLADIMÍR \\ Department of Kinesiology, Faculty of Sports Studies, Masaryk University, Brno, Czech Republic
}

\begin{abstract}
Pavel, K. \& Vladimir, H. (2014). Temporal gait characteristics in the Czech adult population. J. Hum. Sport Exerc., 9(Proc1), pp.S546-S551. A descriptive comparative research study of gait of the Czech population has been carried out. Its aim was to assess temporal characteristics of a stance in the Czech population in relation to the BMl and age. To obtain basic data the Pedar Mobile System (Novel GER) with capacitative insoles was used. 170 men and women aged 18-60 divided by gender and age into three natural biological groups (18-30, 31-45, 46-60 years of age) were measured (Kovár 1997, Riegrová 1998, Pavlík 2007). Basic temporal characteristics of a stance were selected focusing on a comparison of the duration of the initial and terminal double limb stances and the single limb stance between the individual groups. These variables were assessed in relation to age and the BMI using ANOVA, Tukey HSD test and Pearson product-moment correlation coefficient to assess the results. The statistical significance level was set at $\alpha=0.05$. There were no significant differences found in the main observed variables, i.e. the initial and terminal double limb stances and the single limb stance in any age groups, neither in women or men in terms of age and BMI. The only difference detected was in the swing time in both the younger groups and the oldest group of participants in cases where they were not divided by gender. The swing time got significantly reduced in the oldest age category. The moderate correlation coefficient was found between the selected characteristics of a stance and the $\mathrm{BMI}$ or age for all the groups $(r=0,3-0,5)$. This means that neither the BMI nor age significantly affect the initial and terminal double limb stance time and the single limb stance time in the observed research participants aged 60 and below. Keywords: STANCE, AGE, BMI.
\end{abstract}

\footnotetext{
Corresponding author. Department of Kinesiology, Faculty of Sports Studies, Masaryk University, Brno, Czech Republic E-mail: korvas@fsps.muni.cz 8th INSHS International Christmas Sport Scientific Conference, 5-7 December 2013. International Network of Sport and Health Science. Szombathely, Hungary.

JOURNAL OF HUMAN SPORT \& EXERCISE ISSN 1988-5202

(C) Faculty of Education. University of Alicante

doi:10.14198/jhse.2014.9.Proc1.45
} 


\section{INTRODUCTION}

Walking is a basic human skill. It is an individual expression of a motion, which develops dynamically, especially during childhood. In later years its quality is affected by many factors brought about by adolescence, age, amount of physical activity, use of walking during the day, week, etc. Since the second half of the last century an increasing tendency to neglect the need for physical activity has been observed in the modern man (Frollis, 1988; Blair et al., 1989; Blair et al., 2001; Blahutková et al., 2005) Frolis (1988), for instance, indicates a sharp reduction in physical activity during the 20th century from $100 \%$ to mere $1 \%$ percent. However, one of the important physical activities which to this day contributes significantly to the total physical activity of our population is walking. It is the most frequently stated activity exercised by $75 \%$ of the population where the average length of daily walking fluctuates between 60-80 min (Neuls \& Fromel, 2007). Compared with other developed countries such as the USA where the average US adult spends mere 24 minutes walking per day (Berkey et al., 2003) and where only $15-30 \%$ of the adult population considers walking the most frequent physical activity (McArdle et al., 1986) the Czech population may still be viewed as a "walking" nation. Due to its low realization demands and easy motion structure, walking is considered important for the maintenance of optimal functions in older people but nowadays it may perform the same function in younger age groups as well.

The areas most commonly treated in studies dealing with walking include the evolution of motion structures, correct involvement of the musculoskeletal system in physical activity, adoption of movement patterns, movement technique, kinematic or dynamic indicators, temporal parameters of a stride, economy and efficiency, and the specifics of walking from the perspective of age, gender, etc. (e.g. Hagemann \& Blanke, 1986; Brach et al., 2008; Perry \& Burnfield, 2010). The development of the movement quality while walking is based on the optimal development of cross locomotor pattern, that is to say on the correct space-temporal involvement of respective muscles and muscle groups (Vojta \& Peters, 1995; Janda et al., 1966; Vele, 2006). A detailed kinesiology characteristic using the analysis of electrical muscle activity during walking is offered in the description of Rose (1994), Vareka \& Varekova, (2009) and Perry \& Burnfield, (2010). A biomechanical analysis of gait has been treated by a number of authors in respect of various factors such as the length of lower extremities, walking speed, terrain slope, etc. (Ayyappa, 1997; Janura, 2004; Kirtley, 2006; Perry \& Burnfield, 2010, and others). Differences between basic parameters of gait, both kinematic and kinetic can be observed especially in younger and older age groups, as well as in healthy people and people suffering from musculoskeletal disorders, and other diseases (Winter et al., 1990; Hayafune et al., 1999, Levine et al., 2012).

Temporal and force characteristics are important indicators of the quality of walking, especially if we focus on a stance. A stance is important for the evaluation of coordination, muscle strength stability and balance of the individual (Perry \& Burnfield, 2010; Kirtley, 2006). The temporal characteristics of gait are maintained for a relatively long period, that is to say changes are usually slow and occur as a result of the decreasing quality of coordination, health, fitness or following a reduction of physical activity or lifestyle change.

Temporal and force characteristics of a stride may be considered one of the fundamental parameters used to determine the quality of walking especially in relation to other variables such as weight, age, health, fatigue, etc. A number of authors have examined these variables and identified their deterioration during lifetime, particularly in the later decades of life (Hagemann \& Blanke, 1886; Kirtley, 2006; Brach et al., 2008; Levine et al., 2012). From this perspective it is possible to use a force and temporal indicators of stride to assess its quality, for the purposes of which the duration of a single-limb stance, initial double-limb stance and terminal double limb stance may be used (Perry \& Burnfield, 2010; Dosla et al., 2013). 
Our study deals with the time and the proportion of these variables to the average value of the entire stance which on average accounts for $60 \%$ of the total stride time while the double-limb phase forms about $20 \%$ of the total stride time. During one stride performed in the course of normal natural walking the given stance phase most frequently displays the following ratio $10-40-10 \%$ (e.g. Perry \& Burnfield, 2010).

Our study focuses on the assessment of the single and double-limb stance times in the course of natural gait in the adult female and male Czech population.

\section{METHODS}

We have performed a cross-sectional and comparative study with research participants representing Czech adult population - both sexes, aged 18-60 - performing regular physical activity. The tested persons predominantly originating from Brno and the surrounding areas were divided by gender and age into three groups according to the natural biological development of organism during adulthood: $A$ : 18-30, B: 31-45, C: 46-60 years of age (Riegerova \& Ulbrichova, 1998; Zvonař \& Pavlik, 2007).

Table 1. Characteristics of the participants divided according to the age and sex.

\begin{tabular}{llllllllll}
\hline Group & \multicolumn{4}{l}{ Age (years) } & \multicolumn{2}{l}{ Height $(\mathrm{cm})$} & \multicolumn{2}{l}{ Weight $(\mathrm{kg})$} & $\mathrm{BMl}$ \\
\hline & $\mathrm{n}$ & $\mathrm{M}$ & $\mathrm{SD}$ & $\mathrm{M}$ & $\mathrm{SD}$ & $\mathrm{M}$ & $\mathrm{SD}$ & $\mathrm{M}$ & $\mathrm{SD}$ \\
\hline W 1 & 31 & 25,0 & 3,9 & 167,3 & 1,2 & 62,3 & 2,2 & 22,3 & 0,6 \\
W 2 & 50 & 37,2 & 4,1 & 137,9 & 0,9 & 65,4 & 1,7 & 23,2 & 0,5 \\
W 3 & 20 & 52,0 & 4,7 & 166,4 & 1,5 & 68,5 & 2,9 & 24,6 & 0,8 \\
M 1 & 23 & 25,0 & 3,6 & 181,2 & 1,4 & 84,5 & 2,6 & 25,7 & 0,7 \\
M 2 & 27 & 35,5 & 3,6 & 182,8 & 1,3 & 83,2 & 2,4 & 24,8 & 0,9 \\
M 3 & 19 & 51,4 & 4,4 & 179,4 & 1,5 & 90,3 & 2,8 & 28,1 & 0,8 \\
\hline
\end{tabular}

Key: W1 - women $18-30$ years old, W2 - women $31-45$ years old, W3 - women $46-60$ years old, $\mathrm{M} 1$ - men $18-30$ years old, $M 2-$ men $31-45$ years old, $M 3-$ men $46-60$ years old

Groups contained various numbers of participants (Table 1 ) with the average age for each group being as follows: A: 25,0 (SD \pm 3.8$)$, B: $36.6 \pm 3.9$ ) and C: 51.7 ( \pm 4.6$)$ years of age. All the persons were instructed on the research plan and agreed to participate. The research was approved by the Ethics Committee of the Faculty.

\section{Instrumentation}

Perpendicular foot pressure on the pad during the take-off was recorded using a mobile system Pedar (Novel, Munich, GER) using two pressure insoles (capacitive pressure insoles in a shoe) which contain 99 pressure sensors evenly distributed over their entire surface. The device also includes a data recorder, flash card and cable kit. The recording was performed at a frequency of $100 \mathrm{~Hz}$. The calibration of shoe insoles is performed using the Pedar branding device. To assess the load the mask was used over the entire surface of the pressure insole.

\section{Protocol}

Laboratory research was carried out while maintaining the standard conditions for all tested persons. The tested persons undertook three attempts where the first two were used for practice and the final one was recorded. The selected parameters were identified in 12 to 15 strides where six of them were assessed, three strides for each leg, always from the second stage of the attempt and not earlier than the sixth stride. The testing was conducted using uniform shoes with flat soles. Each person performed three trials, two training ones and the final one generating research data. The other recorded data included the tested persons' weight, height, age and the BMI. 


\section{Parameters}

Stride time, stance time, swing time, single limb stance time, initial double limb stance time, terminal double limb stance time.

Statistics

ANOVA, Tukey HSD test, Pearson product-moment correlation coefficient. The statistical significance level was set at $\alpha=0.05$.

\section{RESULTS}

Table 2. Temporal characteristics of the selected parameters

\begin{tabular}{lllllll}
\hline & Group & $18-30$ & \multicolumn{2}{c}{ Group $31-45$} & \multicolumn{2}{l}{ Group 46 - 60 } \\
\hline & $\mathrm{M}$ & $\mathrm{SD}$ & $\mathrm{M}$ & $\mathrm{SD}$ & $\mathrm{M}$ & $\mathrm{SD}$ \\
\hline Stride (s) & 1,09 & 0,07 & 1,08 & 0,10 & 1,05 & 0,08 \\
Stance (s) & 0,66 & 0,05 & 0,66 & 0,07 & 0,64 & 0,05 \\
Swing (s) & 0,43 & 0,03 & 0,43 & 0,03 & 0,41 & 0,03 \\
\% stance & 60,67 & 1,20 & 60,62 & 1,31 & 61,01 & 1,36 \\
\% swing & 39,33 & 1,20 & 39,38 & 1,31 & 38,92 & 1,43 \\
\% double1 & 10,65 & 1,25 & 10,62 & 1,25 & 10,96 & 1,40 \\
\% single & 39,44 & 1,17 & 39,43 & 1,23 & 39,09 & 1,53 \\
\% double2 & 10,55 & 1,28 & 10,57 & 1,24 & 11,02 & 1,46 \\
\hline
\end{tabular}

Key: \% stance - percentage out of the stride time, \% swing - percentage out of the stride time, $\%$ double1 - the initial double limb stage percentage out of the stance time, $\%$ single - the single limb stage percentage out of the stance time, $\%$ double2 - the terminal double limb stage percentage out of the stance time

The results in Table 2 indicate the differences between the observed groups are very small. It is clear that there has occurred a slight decrease $(p \leq 0.05)$ in the performance time of three basic gait indicators in the oldest monitored group (stride, stance, swing). On the other hand, if we express the proportion of these basic indicators in per cent, it will change slightly in favour of the single stance phase which becomes slightly longer. If the focus is, however, placed on the main monitored indicators - initial and final double-stance phases, we may observe a slight increase in their length at the expense of the single-stance phase which becomes slightly shortened. Differences between groups concerning the extension of double-stance phase or shortening of the single-stance phase are not statistically significant $(p \leq 0.05)$.

\section{DISCUSSION}

In our study we sought to determine the change tendencies and differences especially in the working age population. If we consider the differences in the selected temporal characteristics of the stride between the chosen groups, it may be argued that the temporal characteristics of gait during normal activity among adults in the younger and middle- biological age are almost identical. Small changes, however, were found in the oldest group for the main indicators monitored. Longer stance time expressed in per cent means the older population needs a longer stance phase during the stride, even though the proportion is still similar to that yielded by other investigations, such as Perry's (2010). This indicates the initiation of a certain trend, which extends both the stance time and double-phase times, which is undoubtedly associated with the biological development, coordination quality, and strength, balance and stability of the motion. In the oldest group there is a tendency indicated here towards 
shortening the stance within one stride. It is therefore interesting to note that if in order to preserve employability even the oldest biological generation of the productive age (46-60 years) has to be physically and mentally active, negative trends in the basic locomotor skills are minimal, i.e. with no significant changes. This may apply for the Czech population below 60 years of age where the detected differences were minimal. As is shown by other studies the significant changes occur at the age of 60 and later (Hageman \& Blanke, 1986; Blanke \& Hageman, 1989; Grabiner et al., 2001; Brach et al.; 2008).

The results achieved raise some general issues related to the physical condition of younger generations as there is no doubt that the biological development clearly reduces fitness in later decades of life. As walking characteristics are very similar to almost identical to those of the biologically youngest group a question arises whether the research participants representing the older generation of the Czech population are perhaps more physically active than would be normally expected or whether the younger groups are already affected by the contemporary phenomenon of a sedentary lifestyle which may be a contributing factor to the gait characteristics of younger generation being comparable with those of older generations.

\section{CONCLUSIONS}

In a sample of the Czech working population up to age of 60 there were no significant differences detected in the temporal characteristics of stride, stance and swing that would document biological changes associated with aging from a developmental perspective.

With the main monitored indicators of the initial and terminal double limb stances and the single limb stance, significant changes that would confirm the presence of changes caused by aging were not detected. Only the oldest group implied a possible tendency towards changes due to aging.

\section{REFERENCES}

1. Ayyappa, R. (1997a). Normal Human Locomotion, Part 1: Basic Concepts and Terminology. J Prosthet Orthot, 9(1), pp.10.

2. Ayyappa, R. (1997b). Normal Human Locomotion, Part 2: Basic Ground-Reaction Force and Muscle Activity. J Prosthet and Orthot, 9(2), pp.49-57.

3. Berkey, C.S. et al.. (2003). One-year changes in activity and inactivity among 10 to 15 year old bioys and girls: Relationship to change in Mody Mass Index. Pediatrics, 111, pp. 592-600.

4. Blahutková, M., Řehulka, E. \& Dvořáková, Š. (2005). Pohyb a duševní zdraví. Brno: Paido.

5. Blair, S.N., Clark, D.B. \& Cureton, K.J. (1989). Exercise and fitness in childhood: Implications for a lifetime of health. In C.V. Gisolfi \& D.L. Lamb (Eds.), Perspectives in exercise science and sports medicine, Vol 2. Youth, exercise and sport (s.401-430). Indianapolis: Benchmark Press.

6. Blair, C.N., Dunn, A.L., Marcus, B.A., Carpenter, R.A. \& Jaret, P. (2001). Active living every day. Champaign, Human Kinetic.

7. Blanke, D.J. \& Hageman, P.A. (1989). Comparison of gait of young men and elderly men. Phys Ther, 69, pp.144-148.

8. Brach, J.S., Studenski. S., Perera, S. et al. (2008). Stance time and step width variability have unique contributing impairments in older persons. Gait Posture, 27, pp.431-439.

9. Došla, J., Korvas, P., Zvonař, M., Musil, R., Šenkýř, J., \& Kalina, T. (2013). Comparison of selected characteristics of gait in men and women. Journal of Human Sport and Exercise, 8(2), pp.114-119.

10. Frollis, V.V. (1988). Ageing, life extending. Leningrad: Nauka. [in Russia]

11. Frömel, K., Nykodým, J. et al. (2006). Intensity and volume from 15 to 69 years of Czech population. Česká kinantropologie, 1(10), pp.13-29. [in Czech] 
12. Gabell, A. \& Nayak, U.S.L. (1984). The effect of age and variability in gait. J Gerontology, 39, pp.662-6.

13. Grabiner, P.C., Biswas, S.T. \& Grabiner, M.D. (2001). Age-related changes in spatial and temporal gait variables. Arch.Phys. Med.Rehabil, 82(1), pp.31-35.

14. Hayafune, N. et al. (1999). Pressure and force distribution characteristics under the normal foot during the push-off phase in gait. The Foot, 9, pp-88-92.

15. Hageman, P.A. \& Blanke, D.J. (1986). Comparison of gait of young women and elderly women. Phys Ther, 66, pp.1382-1387.

16. Janda, V., Poláková, Z. \& Véle, F. (1966). The function of the movement system. Praha: SZN.

17. Kirtley, Ch. (2006). Clinical gait Analysis. Theory and Practise. Elswier Limited: Philadelphia.

18. Korvas, P., Musil, R., Došla, J., Kolářová, K., Pavlík, J. \& Šenkýř, J. (2013). The study of vertical ground reaction during walk of Czech women. Journal of Human Sport and Exercise, $8(2)$, pp.54-60.

19. Levine, D., Richards, J. \& Whittle, M.W. (2012). Whittle's Gait Analysis. Churchill Livingstone: Elsevier.

20. Mcardle, W.D., Katch, F.I. \& Katch V.L. (1986). Exercise Physiology (2nd Ed.). Philadelphia PA: Lea \& Febiger.

21. Neuls, F. \& Frömel, K. (2007). Selected correlations of physical activity of Czech girl. Česká kinanatropologie, 11(4), pp.21-32. [in Czech]

22. Ostrosky, K.M., Vanswearingen, J.M., Burdett R.G., Gee Z.A. (1994). Comparison of gait characteristics in young and old subjects. Phys Ther, 74, pp.637-644.

23. Perry, J. \& Burnfield J.M. (2010). Gait analysis; normal and pathological function. Thorofare, N.J.: Slack

24. Riegerová, J. \& Ulbrichová, M. (1998). Aplikace fyzické antropologie v tělesné výchově a sportu. Olomouc: VUT. [in Czech]

25. Vařeka, I. \& Vařeková, R. (2009). Kinesiology of foot. Olomouc: FTK UP. [in Czech]

26. Vojta, V. \& Peters, A. (1995). Vojta 's principle. Praha: Grada. [in Czech]

27. Vele, F. (2006) Kineziology. Praha: Triton. [in Czech]

28. Winter, D.A., Quanbury, A.O., Hobson,D.A. \& ET.AL. (1990). Biomechanical walking pattern ganges in the fit and healthy elderly. Phys. Ther, 70(6), pp.340-347.

29. Zvonař, M., Korvas, P., Kolářová,K., Pavlík, J. \& Musil, R. (2013). The issue of plantar pressure diagnostics in adults. In Pohybová aktivita dospělé populace $v \stackrel{C}{R}$. Hradec Králové: Masarykova univerzita, pp.84-108. [in Czech]

30. Zvonař, M. \& Pavlík, J. (2007) The physical performance of middle and elder population. In Antropomotorika 2007. Banská Bystrica: Univerzita Mateja Bela, pp.212-217. [in Czech] 